\title{
Cell-mediated immunity to myoglobin in polymyositis
}

\author{
RAFAEL HERRERA-ESPARZA, ${ }^{1}$ LEOPOLDO MAGA NA,$^{2}$ \\ JOSÉ MORENO, ${ }^{3}$ ANTONIO FRAGA, ${ }^{3}$ AND CARLOS LAVALLE
}

From the ${ }^{3}$ Rheumatology Department, Hospital de Especialidades, Centro Médico La Raza, IMSS, Mexico DF; the ${ }^{1}$ Immunology Department, Universidad Autónoma de Zacatecas, Zacatecas; and the ${ }^{2}$ Immunology and Microbiology Laboratory, Hospital General, Centro Médico La Raza, IMSS, Mexico DF, Mexico

SUMMARY Using the leucocyte migration inhibition (LIF) test we looked for evidence of cellmediated hypersensitivity against myoglobin in 8 patients with polymyositis (PM) or dermatomyositis (DM). The migration index for PM-DM patients was $47 \cdot 5 \pm 17 \%$, while in the controls the index was $86 \pm 12 \%(\mathrm{p}<0 \cdot 001)$. The presence of serum antibodies against myoglobin was also investigated by passive haemagglutination $(\mathrm{PH})$ and counterimmunoelectrophoresis (CIE). By $\mathrm{PH}$ the reciprocal titre of antimyoglobin antibodies was $150 \pm 28$ in PM-DM compared with $16 \cdot 2 \pm$ 15.9 and $8 \cdot 7 \pm 7 \cdot 7$ in control patients with diseases $(\mathrm{p}<0.01)$ and negative in normal persons. CIE showed antimyoglobin antibodies in 3 PM-DM patients and in none of controls. Cell-mediated immunity against myoglobin may be implicated in the pathogenesis of PM. The pathological significance of antimyoglobin antibodies remains to be determined.

Polymyositis (PM) is an inflammatory muscle disease that affects mainly proximal muscular groups; when the skin is affected it is called dermatomyositis (DM). The aetiology is unknown and the pathogenesis obscure; however, some immunological features have been described. These include direct mononuclear cytotoxicity to muscle fibres ${ }^{12}$ and lymphotoxinmediated cytotoxicity to fetal muscle when PM-DM mononuclear cells have been previously cultured with autologous muscle extract. ${ }^{3}$ Furthermore, when patients' mononuclear cells are stimulated in culture with muscle tissue they undergo blastogenesis. ${ }^{24}$

Several autoantibodies have been found in PM-DM patients, including anti-PM- $1,{ }^{56}$ the Jo-1 antibody system, ${ }^{7}$ antimyosin, ${ }^{8}$ and antimuscle antibodies. $^{9-12}$ In addition deposits of immunoglobulins and complement have been reported ${ }^{13}{ }^{14}$ in the vessel walls of involved muscles. By passive haemagglutination Nishikai and Homma ${ }^{15}$ found antimyoglobin antibodies in patients with PM-DM, while in control groups and in patients with other myopathies such antibodies were either absent or in very low titre. To our knowledge no specific muscle antigen has been implicated in cell-mediated hypersensitivity to muscle in PM-DM patients. Myoglobin is a major

Accepted for publication 2 February 1982.

Correspondence to José Moreno, MD. Rheumatology Department, Hospital de Especialidades, Centro Médico La Raza, IMSS, México, D.F. 07870, México. component of striated muscle and is not found in smooth muscle. We therefore sought evidence of delayed hypersensitivity and specific antibodies directed against myoglobin in patients with PM-DM.

\section{Materials and methods}

Patients. Eight patients with PM-DM according to the criteria proposed by Bohan and Peter ${ }^{16}$ were studied. Three had polymyositis, 4 typical dermatomyositis, and one childhood dermatomyositis. None had either associated neoplasia or overlap syndrome. Two patients were considered active, as defined by high serum enzyme levels, muscle tenderness, mild fever in the absence of infection, and high sedimentation rate (Wintrobe). Other conditions producing high serum enzyme levels were ruled out. Seven patients were receiving prednisone $(5$ to $60 \mathrm{mg}$ per day); 2 were also receiving azathioprine (100 and $150 \mathrm{mg}$ daily), and one patient was untreated at the time of the study. The normal control group comprised 8 healthy individuals. Control disease groups were 8 patients with systemic lupus erythematosus (SLE) who had 4 or more ARA criteria ${ }^{17}$ and 8 with classic or definite rheumatoid arthritis (RA) according to the ARA criteria ${ }^{18}$ These disease groups were included only in the serological studies.

Preparation of patients' cells. Peripheral blood was obtained by venepuncture with heparinised syringes and left to sediment spontaneously for 90 minutes. The 
leucocytes in the supernatant plasma were washed thrice in Hanks's balanced salt solution (HBSS). After the last washing the cells were resuspended in 199 medium (Difco, Detroit, Michigan) and adjusted to a concentration of $20 \times 10^{6}$ per ml. Viability always exceeded $95 \%$ by trypan blue exclusion.

Myoglobin isolation and purification. Myoglobin was isolated by a modification of Singer's method. ${ }^{19}$ Human muscle fragments were obtained within 2 hours of death and stored at $-70^{\circ} \mathrm{C}$. The fragments were minced and homogenised, and, except where noted, the $\mathrm{pH}$ was maintained at $7 \cdot 0$ during the procedure. The unpigmented proteins were precipitated with $0.5 \mathrm{M}$ basic acetate. The supernatant was treated with phosphate mixture $\left(\mathrm{Na}_{3} \mathrm{PO}_{4} 160 \mathrm{mg}\right.$, $\mathrm{Na}_{2} \mathrm{HPO}_{4} 40 \mathrm{mg}$, for each $20 \mathrm{~g}$ of muscle), and dialysed against ammonium sulphate solution in progressive concentrations from 40 to $100 \%$ for 8 to 24 hours. After the last dialysis the metamyoglobin was precipitated at the bottom of the dialysis bag. To remove the sulphate from the myoglobin a further 24-hour dialysis against phosphate buffered saline

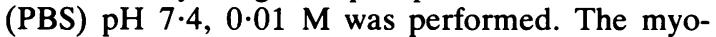
globin extract was purified by Sephadex G-50 gel filtration (Pharmacia Fine Chemicals, Uppsala, Sweden) in a $2.6 \times 60$ column (Pharmacia) at an elution speed of $60 \mathrm{ml}$ per hour, and $3 \mathrm{ml}$ samples were collected in glass tubes with an LKB-8300 Uvikord II fraction collector. Myoglobin purity was assessed by cellulose acetate gel electrophoresis in a Beckman 110 densitometer. Further characterisation of myoglobin was in a Carl-Zeiss PMQ-II spectrophotometer. Protein concentration was determined by Lowry's method. ${ }^{20}$ The myoglobin sample was sterilised by Millipore filtration with 22 $\mu \mathrm{m}$ pore size (Millipore Corp., Bedford, MA).

Leucocyte migration inhibition (LIF) test. The LIF test was done according to modified Bendixen and Søborg's method. ${ }^{21}$ Briefly, Mackaness type migration chambers (Falcon Plastics, Oxnard, CA) were filled with either 199 medium alone or 199 medium containing $1 \%$ myoglobin. The cells were taken up in capillary tubes (Propper Manufacturing Co. Inc., Long Island City, NY) and centrifuged at $200 \mathrm{~g}$ for 15 min. Portions of the capillaries containing the cell pellets were placed in the chambers. Experiments were done either with PM-DM cells or with healthy donor cells. The chambers were incubated for 48 hours at $37^{\circ} \mathrm{C}$. Each assay was done in quadruplicate, and results were included only when reproduced at least 3 times. The migration areas were measured by projection on paper, the shaded areas being cut out and weighed in a precision balance. The migration index was defined as:

$\%$ Migration $=\frac{\text { mean area of migration of cells plus antigen }}{\text { mean area of migration of cells alone }} \times 100$.
Absorption of sera. Sera were heat-inactivated at $56^{\circ} \mathrm{C}$ for $30 \mathrm{~min}$ and then in order to remove heterophile antibodies were absorbed for one hour with sheep red blood cells (SRBC) at room temperature.

Passive haemagglutination $(P H)$. SRBC were coated with human myoglobin by the technique described by Nishikai and Homma. ${ }^{15}$ Myoglobincoated tanned SRBC (My-SRBC) were resuspended at $5 \%$ in HBSS. The PH assays were done in Microtiter U-plate mictowells (Cooke Engineering, Alexandria. VA) containing $0.2 \mathrm{ml}$ of $0.5 \%$ heatinactivated rabbit serum in HBSS, $0.2 \mathrm{ml}$ of either patient or control serum in dilutions from 1:10 to $1: 160$, and $0.2 \mathrm{ml}$ of My-SRBC suspension. The U-plates were first incubated for $60 \mathrm{~min}$ at $37^{\circ} \mathrm{C}$ and then overnight. After 18 hours' incubation the haemagglutination in each microwell was recorded.

Counterimmunoelectrophoresis (CIE). This was done in a Hyland unit (Hyland, Costa Mesa, CA) by the method of Gocke and Howe. ${ }^{22}$ Plastic $10 \times 10$ plates with $2 \%$ agarose (Sigma Chemical Co., St Louis, MO) prepared in barbital buffer $0.05 \mathrm{M}, \mathrm{pH}$ $7 \cdot 2$ were used. The running time was 45 minutes at 30 $\mathrm{mA}$. The myoglobin was placed in the cathode well at a concentration of $5.5 \mathrm{mg} / \mathrm{ml}$.

Statistical analysis was by Student's $t$ test.

\section{Results}

ANTIGEN

After Sephadex G-50 gel filtration of human myoglobin (Fig. 1) the cellulose acetate gel electrophoresis showed that it was pure myoglobin with beta electrophoretic migration pattern. Spectrophotometric characterisation showed 2 peaks at 502 and $624 \mathrm{~nm}$, confirming its nature (Fig. 2). The protein concentration in the sample was $5 \cdot 5 \mathrm{mg} / \mathrm{ml}(5 \cdot 5 \mathrm{~g} / \mathrm{l})$.

LIF TES T

When incubated with 199 medium alone the PM-DM leucocyte migration area was taken as $100 \%$ and did not differ from that of the control leucocytes incubated in the same way. When PM-DM cells were incubated in presence of myoglobin the migration index was $47 \cdot 5 \pm 17 \%$ (range $10-63 \%$ ), significantly less than the control index when incubated with myoglobin, which was $86 \pm 12 \%(p<0 \cdot 001)$. Fig. 3 shows the individual migration indices.

\section{PASSIVE HAEMAGGLUTINATION}

All the PM-DM patients had antibodies to myoglobin, their mean reciprocal titre being $150 \pm 28$ (range 80 to 160 ). Values for the disease controls were $16 \cdot 2 \pm 15 \cdot 9$ for RA and $8 \cdot 7 \pm 7 \cdot 7$ for SLE, both differences being significant $(p<0 \cdot 01)$. Healthy control sera were all negative (Fig. 4). 


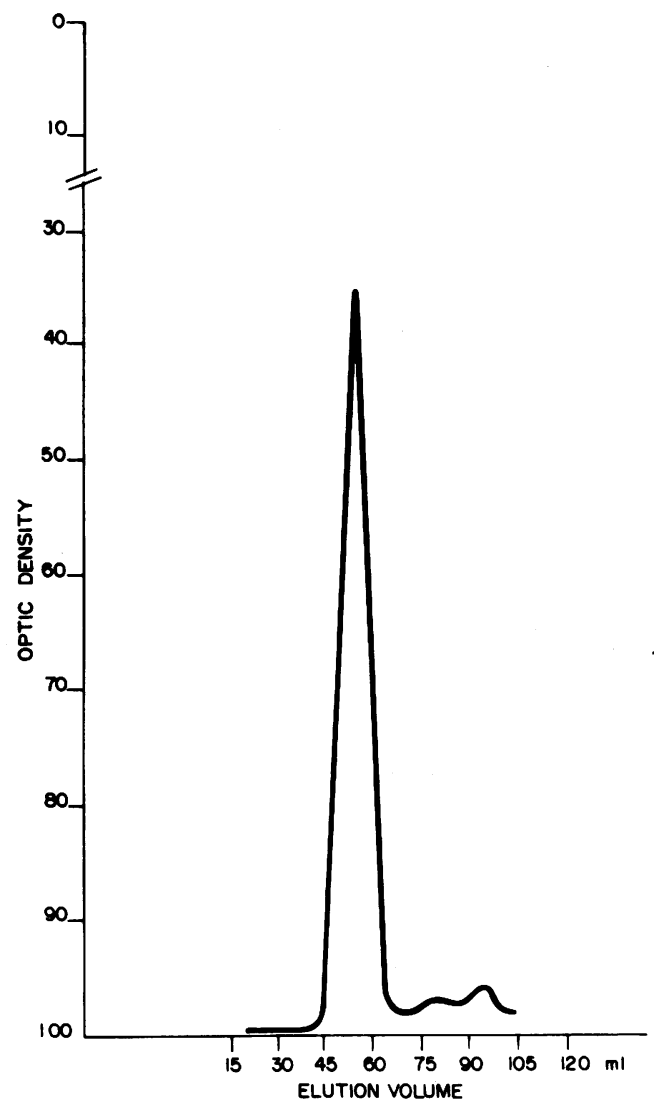

Fig. 1 Sephadex G-50 gel filtration chromatography of human myoglobin. The elution speed was $60 \mathrm{ml}$ per hour, myoglobin eluted from fractions 15 through $23(3 \mathrm{ml}$ fractions were collected). The graph was plotted in an LKB spectrophotometer fraction analyser.

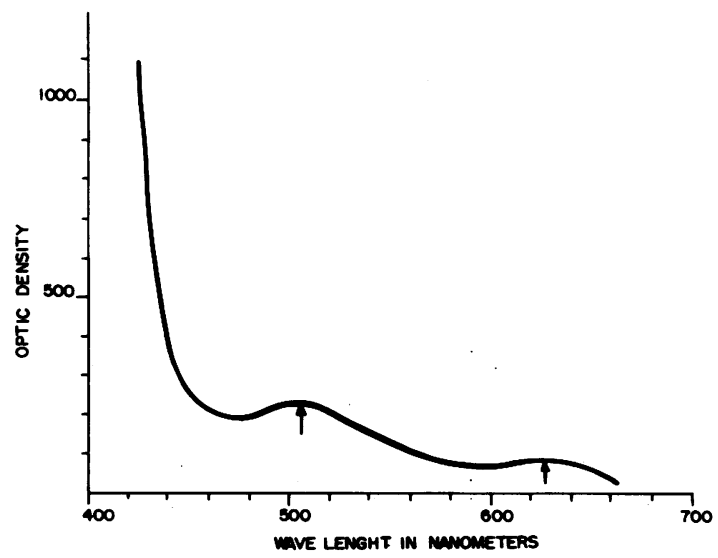

Fig. 2 Spectrophotometric characterisation of human myoglobin in 0.01 M PBS, pH 7.4. The characterisation was done from 400 to $700 \mathrm{~nm}$. The absorption spectrum $(502$ and $624 \mathrm{~nm}$ ) is characteristic of myoglobin.

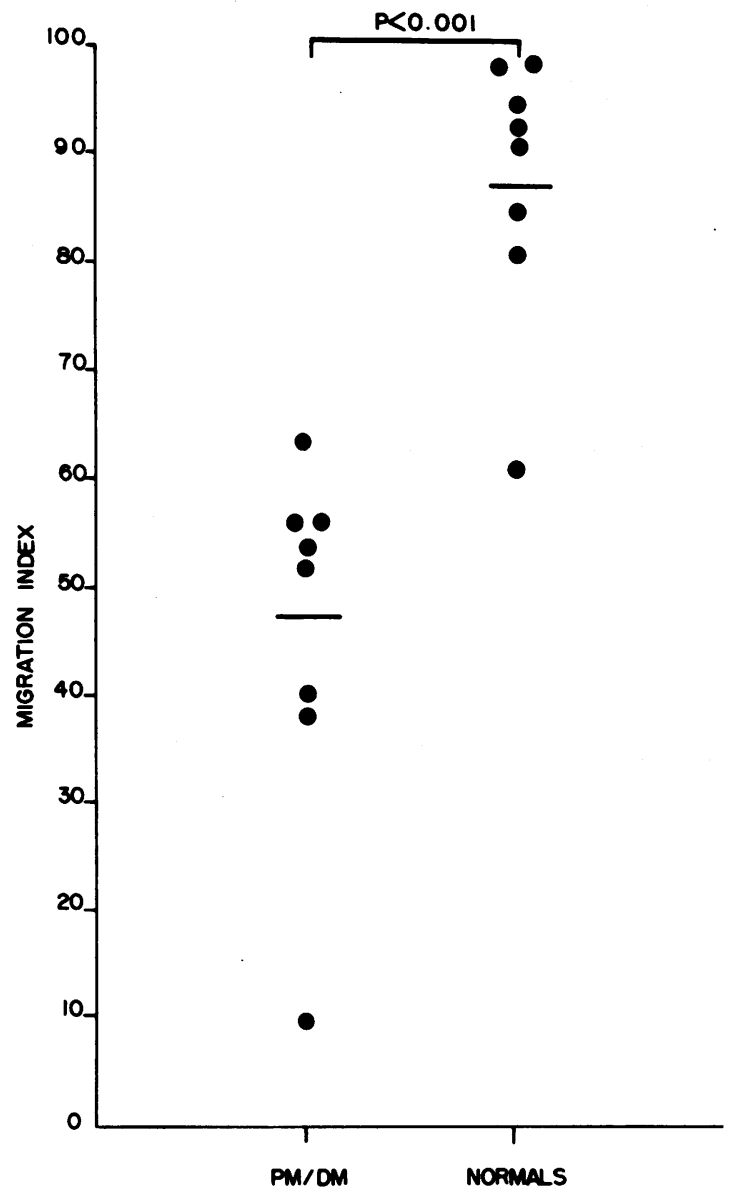

Fig. 3 LIF test to myoglobin. The differences between $P M-D M$ patients (left side) who had a migration index from 10 to $63 \%$ are evident when compared with normal persons who had a range from 60 to $100 \%$ (see text).

In order to define the antimyoglobin specificity found by $\mathrm{PH}$, absorption studies were done as follows: sera were incubated for $30 \mathrm{~min}$ at $37^{\circ} \mathrm{C}$ with $1 \%$ myoglobin solution in $0.01 \mathrm{M}$ PBS. All sera tested in this way became negative for antimyoglobin activity by PH. A further attempt to define this specificity was by indirect immunofluorescence with mouse muscle as substrate. By this method all sera showed 2 staining patterns: both sarcolemmal and sarcoplasmatic. When sera were previously absorbed with MySRBC, the sarcoplasmatic staining disappeared and sarcolemmal remained positive (data not shown).

Counterimmunoelectrophoresis was positive in only 3 of the 8 patients, 2 of them with active disease. All the controls were negative. 


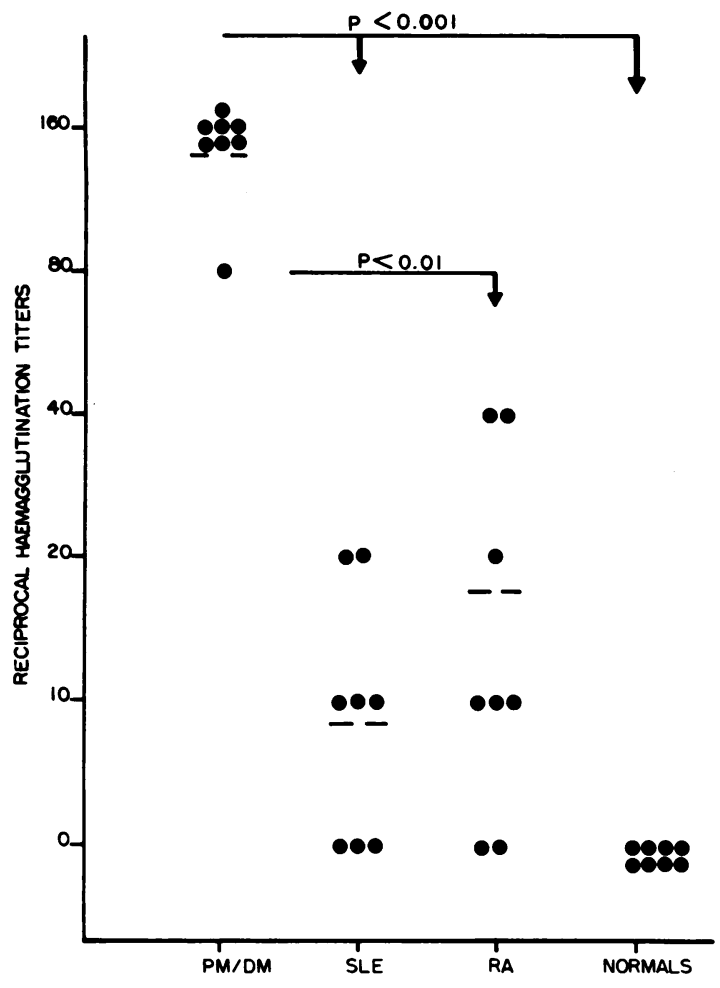

Fig. 4 My-SRBC passive haemagglutination by PM-DM sera. The highest titre tested was 1:160. By this method all patients had antimyoglobin antibodies at titres of 1:80 or more; 5 SLE and $6 R A$ patients had antimyoglobin antibodies at titres of 1:40 (2 patients) or below (see text).

\section{Discussion}

We have demonstrated cell-mediated hypersensitivity to myoglobin by the LIF test in patients with PM-DM and confirmed the presence of antimyoglobin antibodies by $\mathrm{PH}$. No previous study has reported cell-mediated immunity to a specific muscle antigen in PM-DM.

In PM-DM the cellular infiltrates in the inflamed muscles are mainly mononuclear, suggesting that a cell-mediated immune mechanism produces the tissue injury. Our findings are in accordance with this hypothesis. Several studies ${ }^{1-4}$ have found evidence of cell-mediated immunity against muscle in PM-DM, and our findings suggest that myoglobin is acting as antigen in this respect. Recently $\mathrm{Haas}^{23}$ failed to find antimuscle cytotoxicity with PM-DM mononuclear cells using xenogeneic target cells of rat origin. In our study the myoglobin was of human origin, so that in PM-DM the aberrant cellular immune response may be directed against antigenic determinants of myoglobin not shared by these 2 species, which does not seem to be the case for the humoral response, since antimyoglobin antibodies were absorbed with mouse muscle. Another possible explanation for these discrepancies may be the different systems tested.

LIF production is a feature of delayed hypersensitivity. ${ }^{24}$ Other mechanisms capable of producing migration inhibition seem unlikely to explain our results. Immune complexes ${ }^{25}$ inhibit cell-migration in a nonspecific way; in our experiments the cells were washed to remove plasma components. Nevertheless immune complexes may have been membranebound to the polymorphonuclear leucocytes, and we did not exclude this possibility. However, circulating immune complexes are not a recognised feature of PM-DM. Further, the cells migrated normally when incubated in the absence of myoglobin. Fibrin aggregates may also interfere with migration, ${ }^{26}$ but in the present study the blood was heparinised, and washing the cells removed clotting factors.

Antimyoglobin antibodies were detected by $\mathrm{PH}$ in all the patients with PM-DM and, at lower titres, in some of disease controls. The absorption studies confirmed its specificity. The method used is highly sensitive. CIE was positive in only 3 patients and in none of the controls. This method is less sensitive but highly specific for antimyoglobin antibodies.

What incites the immune response against myoglobin in PM is unknown. While we have shown that in PM-DM there is cell-mediated immunity against myoglobin, we do not know whether it occurs as a primary event and is responsible for the tissue damage, or whether it is secondary to muscle injury. Further studies are required to define the significance of these findings.

\section{References}

1 Dawkins R L, Mastaglia F L. Cell-mediated cytotoxicity to muscle in polymyositis. $N$ Engl $J$ Med 1973; 288: 434-8.

2 Saunders M, Knowles M, Currie S. Lymphocytic stimulation with muscle homogenate in polymyositis and other muscle wasting disorders. J Neurol Neurosurg Psychiatry 1969; 32: 569-71.

3 Johnson R L, Fink C W, Ziff M. Lymphotoxin formation by lymphocytes and muscle in polymyositis. J Clin Invest 1972; 51: 2435-49.

4 Esiri M M, Maclennan I C M, Hazleman B L. Lymphocyte sensitivity to skeletal muscle in patients with polymyositis and other disorders. Clin Exp Immunol 1973; 14: 25-35.

5 Reichlin M, Mattioli M. Description of a serological reaction characteristic of polymyositis. Clin Immunol Immunopathol 1976; 5: 12-20.

6 Wolfe J F, Adelstein E, Sharp G C. Antinuclear antibody with distinct specificity for polymyositis. J Clin Invest 1977; 59: 176-8.

7 Nishikai M, Reichlin M. Heterogeneity of precipitating antibodies in polymyositis and dermatomyositis: characterization of the Jo-1 antibody system. Arthritis Rheum 1980; 23: 881-8.

8 Caspary E A, Gubbay S S, Stern G M. Circulating antibodies in polymyositis and other muscle-wasting disorders. Lancet 1964; ii: 941.

9 Grace J T, Dao T L. Dermatomyositis in cancer: possible etiological mechanism. Cancer 1959; 12: 648-50. 


\section{Herrera-Esparza, Magaña, Moreno, Fraga, Lavalle}

10 Curtis A C, Heckamann J H, Wheeler A H. Study of the autoimmune reaction in dermatomyositis. JAMA 1961; 178: 571-3.

11 Copeman P, Alexander S. Dermatomyositis. Adenocarcinoma of male breast. Detection of antibodies to neoplasm in serum. Proc $R$ Soc Med 1967; 60: 183-4.

12 Alexander S, Forman L. Dermatomyositis and carcinoma. A case report and immunological investigation. $\mathrm{Br} \mathrm{J}$ Dermatol 1968; 80: 86-9.

13 Tan E M, Reid R T, Pearson C M. Autoallergic diseases with serum IgG reactive with vascular structures. Arthritis Rheum 1970; 13: 353.

14 Whitaker J N, Engel W K. Vascular deposits of immunoglobulin and complement in idiopathic inflammatory myopathy. $N$ Engl J Med 1972; 286: 333-8.

15 Nishikai M, Homma M. Circulating antibody against human myoglobin in polymyositis. JAMA 1977; 237: 1842-4.

16 Bohan A, Peter J B. Polymyositis and dermatomyositis. $N$ Engl J Med 1975; 292: 344-7, 403-7.

17 Cohen A S, Reynolds W E, Franklin E C, et al. Preliminary criteria for the classification of systemic lupus erythematosus. Bull Rheum Dis 1971; 21: 643-8.

18 Ropes N W, Bennett G A, Cobb S, Jacox R, Jessar R A. Proposed diagnostic criteria for rheumatoid arthritis. Bull Rheum Dis 1956; 7: 121-4.
19 Singer K, Angelopolus R, Ramont B. Studies of human myoglobin. I. Myoglobin in sickle cell disease. Blood 1955; 10: 979-86.

20 Lowry H O, Rosenbourgh N J, Farr A L, Randall R J. Protein measurement with the folin-phenol reagent.J Biol Chem 1951; 193: 265-75.

21 Bendixen G, Søborg M. A leukocyte migration technique for in vitro detection of cellular (delayed type) hypersensitivity in man Dan Med Bull 1969; 16: 1-6.

22 Gocke D J, Howe C. Rapid detection of Australia antigen by counterimmunoelectrophoresis. J Immunol 1970; 104: 1031-2.

23 Haas D C. Absence of cell-mediated cytotoxicity to muscle cultures in polymyositis. J Rheumatol 1980; 7: 671-6.

24 Rocklin R E. Products of activated lymphocytes: leukocyte inhibitory factor (LIF) distinct from migration inhibitory factor (MIF). J Immunol 1974; 112: 1461-6.

25 Spitler L, Huber H, Fudenberg H H. Inhibition of capillary migration by antigen-antibody complexes. J Immunol 1969; 102: 404-11.

26 Hooper K E, Geczy C L, Davies W A. A mechanism of migration inhibition in delayed-type hypersensitivity reactions. I. Fibrin deposition on the surface of elicted peritoneal macropahges in vivo. J Immunol 1981; 126: 1052-8. 